\title{
Musical meaning and social reproduction: a case for retrieving autonomy
}

\section{Lucy Green}

Music educationalists are probably agreed upon one thing if nothing else: that theory and practice in the field urgently need to embrace diversity. This might encompass the diversity of musical styles which the globalisation of the music industry with one hand is making widely available, and with the other hand is threatening to swamp; the localisation of traditional musics being bolstered by that same industry as well as by governments and pressure groups in response to such threats; the appropriation and reworking of global musical styles in local settings, with and without the 'help' of commercial interest; the diverse responses to and uses of musics in different places, by different ethnic groups, religions, social classes, genders, 'sub-cultures', 'scenes' and other social groups; the rapidly changing array of music technology which is impacting on approaches to music-making; or the diversity of musical reception practices and approaches to music teaching and learning. How can music education philosophers and theorists, let alone practitioners, come to grips with such factors?

At the present time, the Adornian project of discerning within music, traces of the structure and ideology of the society from which that music springs, has been largely discarded. Sociological interest in music is focussing instead on questions of how musical meanings are constructed through discourse, use, education, the media and other social practices and institutions, at the levels both of face-to-face interaction and of wider social structures (Martin, 1995; Finnegan, 1989; Negus, 1999; DeNora, 2000 and 2003; Clayton 2003). What people say about music, the uses to which they put it in their ordinary lives, and their music-making practices are all receiving interest from researchers and scholars, alongside questions about the structures and processes of the music industry and broadcasting corporations and perhaps to a lesser extent, of education. Musicology has come under attack from such quarters during the last fifteen years or so, most notably for 
its alleged formalism and its implicit attribution of autonomous status to Western classical music. That is, it has been accused of concentrating on the sounds of music, the musical 'text', to the detriment of music's social contexts and uses, and for harbouring an assumption that the value and significance of the musical text rise above particular social and historical conditions. But we must be careful not to swing too far in the opposite direction. To consider the discourse and use surrounding music without taking into account the ways in which the musical text is organised, can altogether miss out the quality of the very object of consideration, so that in the end it could be food or clothes that are under discussion rather than music with its own peculiar properties.

In this article I propose a theory of musical meaning and experience which takes into consideration the dialectical relationship between musical text and context, and which is flexible enough to apply to a range of musical styles. Through this theory I examine the roles played by the school music classroom which, despite the multiplicity of musical styles now incorporated into schooling, continues to contribute to the reproduction of existing social relations in the wider society. I consider how music itself can be understood to construct and communicate apparent 'truths' about ourselves and society and what role the classroom plays in perpetuating those 'truths'. Finally I argue for a partial but necessary reinstatement of the much-maligned notion of musical autonomy as a critical moment in any attempt to change things.

\section{Musical meaning and experience}

What causes us to recognise a particular concatenation of sounds as being music? If we hear the sounds of a lorry backing into a side-street, or a steel-pan being tuned, we don't consider them to be music. In order to do so, the listener has to be immersed in a complex range of social conventions, which are discernible in relation both to the organisation of the sounds themselves, and to the social contexts surrounding their production and reception.

Sound is the raw material from which music is made. For music to come into existence and for musical experience to occur, this raw material must be organised in such a way as to have relationships which are perceived in the mind of a listener. For example, the listener might notice features such as patterning, opening and close, whole and part, 
beginning and end, repetition, similarity, difference, and so on. These features are perceptible in several ways. One is that the flow of musical materials through time is organised in such a way as to cause listeners to anticipate future sonic events, as L. B. Meyer (1956) so persuasively demonstrated with reference to Western classical music, and which can equally be referred to many other classical, popular and traditional musics. We wait for the final chord or the next note after the pause, we expect the music to break out into a melody at the next strong beat, we hear the string flourish or the drummer's extended up-beat as an announcement of the reprise, and so on. Not only does music raise expectations for what might be going to happen next, it also causes us to make retrospective connections between present and past events, so that the present makes the past meaningful; and the musical past colours the present just as much as the present raises expectations for the future. In many musics, perhaps even most, expectation and retrospection seem to play a relatively small part in the experience. On one hand, experienced is focussed on the quality of the sounds: texture, timbre, a crack in the voice, a pitch inflection so slight as to be barely noticeable; on the other hand, experience takes in a wide field of processual flow, such as the feeling of being carried along on a relentless beat. But of course that quality, or that sense of travelling along, nonetheless only comes into existence in relation to what went before and what comes afterwards at any particular moment.

The mental acts involved in processing music backwards and forwards in time, and attending to the quality of the moment or processual flow, involve the making of meaningful connections between parts of the music being heard. But these connections are not restricted to the particular piece of music in question, for they arise from the listener's previous experience of a number of pieces of music that together make up a style, sub-style or genre. Thus the connections can cut across from one piece of music to another. I am not referring here to a postmodern concept of intertextuality; indeed what is meant by intertextuality has been going on between pieces of music, by necessity, since the first music emerged into history. For no music can exist, that is, no music can be perceived as music, without reference to a higher-order organising factor, or what can be termed a style; and virtually all music has always 'borrowed', imitated or directly implanted components from other pieces. Perception of the connections within and across pieces of music is learnt, acquired through repeated listening and therefore, through some 
level of familiarity with the style of the music in question. If the listener does not have familiarity, relatively few meanings will be conceived. Therefore a piece of music which is highly meaningful or very rewarding to one individual, might be relatively meaningless or lacking in interest to another. Any one piece of music can give rise to a multiplicity of possible meanings.

I refer to the meaningful connections that are forged within and across musical pieces, as 'inherent musical meanings' (Green, 1988; 1997). The word 'inherent' has at least two meanings in the English language. It can mean that a property of an object is essential, ahistorical or natural, which is quite the opposite of how I am using the term. It can also mean that a property of an object is contained within the object, but without any suggestion of this containment being essential, ahistorical or natural. This is how I am using the term. 'Inherent musical meanings' are 'inherent', in the sense of being contained within the musical object, in relation to the historically-constituted, logical properties of the meaning-making processes. These processes involve meaning-making constituents, or to put it crudely, 'signs' which are made of musical materials (a chord, a note, a phrase); and meanings-being-meant corresponding with 'referents' (the anticipated chord or note, the re-cognised melody) that are also made up of musical materials. Both 'signs' and 'referents' are incorporated, embodied, or they inhere and are thus inherent within the raw materials that constitute the music in question. However, they are of course entirely socially constituted, and recognition of them, as I have already suggested, is dependent on listeners' acquired familiarity with the stylistic norms of the music in question. To return to the example of the lorry backing into a side-street or a steel-pan being tuned: such sounds could only become music and therefore only carry musical meaning by virtue of a complex set of social conventions. The organisation of the materials into meaningful relationships, or what I call inherent musical meanings, is one such convention.

Someone could object to my claim that musical experience relies on the listener making connections between the past, present and future of the musical materials, as follows: that if we turn on the radio and hear only the shortest snatch of sound, less than a second, we can still tell it is music that we are hearing, rather than, say, a spoken voice, a lorry turning or some other sound. We can tell this even though we are quite unable to make 
any connections between the snatch of sound that we heard and any ones that preceded it or followed after it. How then can we recognise the sound as music, if it is the case that such recognition requires a perception of inherent meanings arising from making connections between parts of the music as they pass in time, as suggested above? One response is to say that we do not actually have a musical experience in that situation. Rather we recognise that the snatch of sound comes from one or more musical instruments or sung voices, and we assume that because it was heard on the radio, putting two and two together, it must be part of a piece of music.

This is so, but there is in fact something else going on which is of much deeper significance. For our assumption that the snatch of sound comes from a piece of music derives from a quite different aspect of musical meaning, an aspect that relates not to the interrelationships of musical materials, that is not to musical inherent meanings; but to music's social context and its mediation as a cultural object through historical social institutions. In other words, it derives from musical meanings which point outwards from the musical text towards concepts, relationships or things that exist independently of it. I refer to such meanings as 'delineations', (Green, 1988; 1997) in other words, as meanings which are loosely suggested or metaphorically sketched by the music in relation to its social context. Factors such as the clothes and hairstyles of the musicians, their listeners or fans; the venues in which the music is relayed; the social or political values associated with the music, which may or may not be embodied in lyrics; the musical practices of the listeners, and indeed other social practices connected with them, and so on, all come into play.

Any particular piece of music may mean something we can relate to, something we dislike, something we desire and so on. Individuals will have a multiplicity of responses to musical delineations, some of which are shared and generally agreed upon by the majority of people in any particular society or social group; others of which will be entirely idiosyncratic. For example a National Anthem delineates the nation, monarchy, president or whatever is relevant to practically everyone in and beyond a particular nation; but to some individuals it can delineate pride whereas to others it delineates shame; to some love, to others hatred. Not only are there obvious examples such as National Anthems, wedding songs, football songs which acquire generally-recognised 
conventional meanings, but there are far more subtle levels of delineation, such as the sound of a particular flute, the way an electric guitar is distorted, a rhythm, a vocal inflection, the precise bend of a pitch; all of which can carry delineated meanings which are conventionally recognised to a greater or lesser extent. A piece of music may also delineate a particular event or feeling that arose on one occasion for one particular individual when she was listening to it, that has nothing whatsoever to do with the meanings conventionally attributed to it by the rest of her society.

Some sociologists of music have argued that it is not possible to fully appreciate a particular piece of music unless one is an insider to, or at least unless one has some insider-knowledge of the culture in which the music was originally produced. Detractors from this position have pointed to the capacity of music to carry across times and places, allowing people from one culture to respond with enjoyment to music from other very different cultures (see the debate between Vulliamy and Shepherd, 1984, 1985 and Swanwick, 1984). Notwithstanding fundamental disagreements, both sides would tend to agree that one can have a fuller, richer understanding if one is an insider; and that if not, the acquisition of some knowledge about the social context in which the music was originally produced is likely to enhance the listening experience. But it is not only the context of production, for unavoidably, the context of reception also contributes to the music's delineations. No music can ever be heard (that is, heard-as-music) outside of a social context. Taking music out of its original context of production and putting it into even a completely new and different context of reception does not cause it to lose delineated meanings; it merely replaces some delineations (related to the context of production) with others (related to the context of reception). We can still have a musical experience even if we know absolutely nothing about the original social contexts, so long as we can recognise the piece as being a piece of music in the first place.

For that recognition to take place we must rely on the perception of inherent meanings. But I have suggested that unless the listener has some familiarity with the style, then no experience of inherent meanings will occur. So to return to the example of the snatch of music on the radio: it is precisely the radio, the social conventions surrounding radio broadcasting, or other circumstances such as the concert platform, the gathering of dancers in the centre of the village and so on, in combination with the musical inherent 
meanings, that tell us it is music we are hearing. In short, recognition of the social, collective definitions of what counts as music is a necessary component of what makes something music. No music can exist at all without its transmitting some delineation or other. Musical delineation is not merely an add-on to inherent musical meaning. On the contrary, it goes on at a fundamental level from the very first moment of recognition of sounds as being music at all. Delineation is therefore as fundamental to musical meaning as inherent meaning and indeed, without experience of musical delineation, no musical experience could come about at all. For without some understanding of the fact that music is a social construction, we would ultimately be unable to recognise any particular collection of sounds as music. So, when we listen to music, we cannot separate our experience of its inherent meanings entirely from an awareness of the social context that accompanies its production and/or reception.

Past commentators have occasionally misunderstood or objected to this understanding of musical meaning, because, they say, the difference between the two aspects of meaning is not clear-cut. I wish to respond to that in two ways, firstly by disagreeing with it, then by agreeing with it. The distinction is clear-cut in a logical sense, in terms of the processes by which the meaning is made. As I suggested earlier, with inherent meaning the 'signs' and the 'referents' all consist of musical materials. A sound refers to another sound either in the same piece of music or beyond it in another piece, or within the style in general terms. With delineated meaning, the 'sign' is made up of musical materials, that is, sounds, but the 'referent' is made up of non-musical constituents related to the social context of the music's production and reception. In short, with inherent meaning the process of signification occurs from sound to sound, whereas with delineation it occurs from sound to non-sound. That encapsulates the logical distinction between the two types of meaning.

Secondly, however, I agree that in other ways the two meanings are not distinguishable, and indeed it is precisely the difficulty of distinguishing between them that interests me most. The point of making the distinction is to contribute to a theoretical understanding of musical experience; but we do not tend to distinguish between the two types of meaning, or to separate them out experientially when engaging in music. This presents no problem for the theory to my mind, quite the opposite in fact, for it is quite normal as 
well as helpful to make theoretical distinctions between things that we find hard to distinguish experientially. Take the example of love. We can theoretically distinguish between different types of love: sexual love, parental love, filial love, love between siblings, love between friends, and so on. We can also make distinctions between other cognate areas, for example liking, desire, lust. But experientially it is not always easy to separate these feelings out from each other, and indeed that difficulty leads to a great deal of confusion and complexity in our lives. But that does not mean we give up the idea of making the distinctions theoretically, for there are so many cases where they are clear and helpful. The fact that other areas exist where they are confused, only serves to remind us of the complexity of human culture, and that theory is a mere tool to help us achieve a better understanding of that complexity, rather than undermining theory per se, or refuting a particular theory. So it is with the dialectical theory of musical meaning which I am putting forward here.

Although as I have argued, our prior experiences and our social circumstances will greatly affect our responses to music, they cannot be said to be wholly determining factors. For even though music relies on social convention for its existence, this does not mean that it has no objective properties which would carry across different social contexts, or which lend themselves more-or-less forcefully to particular types of response or meaningful experience. To that extent music can be said to have objective properties existing independently of convention. Music is not merely a symptom of our musical practices and meanings, but it acts back on us, through its capacity to influence our beliefs, values, feelings or behaviour; or as Moore (2002), De Nora (2000) and E. Clarke (2003) put it, adapting the concept from Gibson (1986, pp. 127-43), it affords different responses. As a simple example: if an adult in any country that I can think of, asks young children to dance to some fast, loud music with an explicit beat, the children are likely to jump around vigorously; if she asks them to dance to some soft, slow music, they will glide about gracefully. To what extent have the children learnt these responses from conventional usage of music in the particular social context to which they are accustomed; and to what extent are these responses natural and universal? It would be hasty to altogether throw out the idea that the responses retain some natural or universal elements. An example of the different types of funeral music or music used in death-rites that can be found in different cultures is often used to point to the social constructedness 
of musical meanings: that in some societies such music is slow whereas in others it is fast. But this does not mean that the same characteristics of music (fast or slow) afford different responses in different social contexts; rather it means that the responses to death and bereavement are different, or are expressed differently.

\section{The dialectics of musical meaning and experience}

The theory which I am putting forward posits a dialectical relationship between the two types of musical meaning identified. Musical experience, in this model, cannot occur at all unless both aspects of meaning are in operation to some extent or other. However, this is not to imply that both types of meaning always co-exist to the same degree, or that we are always conscious of both, or even either, of them. Indeed, our responses to each aspect of musical meaning can be in contradiction, each aspect can have a different effect upon musical experience as a whole, and more interestingly, each can influence and overpower the other.

In order to think through these claims, it is helpful to understand our responses to each aspect of musical meaning in terms of polar extremes, although in practice of course individuals will experience a variety of subtle shades at different points along each pole. Chart A is intended to provide some graphic aid to thinking through these matters. With regards to inherent meaning, we can have a highly affirmative, or positive response. This will occur when we are very familiar with the style or the particular piece, we understand its nuances, and we are carried along securely or pleasurably in its ebb and flow. The greater our familiarity with the style of the music, the more affirmative the experience is likely to be. For when we are familiar with the normative stylistic terms of reference in a piece of music, we are able to distinguish disruption from normality and resolution from disruption. If the music surprises us with, say, an unexpected event, we understand it. Although our expectations may have been negated, we assimilate the negation in terms of a wider field of presence related to other parts of the music and to the style, and thus we enjoy it: without negation, disruption, difference and so on, at whatever level, no inherent musical meaning could arise. Only through these and through our understanding of them do we relate meaningfully to music. Hence ultimately, our negation is understood in the light of its own affirmation: we are negated only because we understand, to whatever 
extent, the style of the music; and we are thus affirmed in our overall musical experience as it takes place in time.

\section{PLEASE INSERT CHART A ABOUT HERE}

At the other extreme, there is a negative response. This is likely to occur when we are unfamiliar with the musical style, for we are then less likely to understand the music, and may have difficulty making sense of it or responding to its internal similarities and continuities, differences and changes. An event which would surprise and delight a listener who has greater familiarity, will go completely unnoticed, so the music seems uneventful and dull. In such circumstances, the capacity of a piece of music to engage our interest is relatively limited. Not being aware of what is and is not normative, we cannot readily distinguish disruption or its resolution, are unable to hear constituent parts as things in themselves, and cannot relate them to other constituents within the piece or across pieces. We therefore receive few, or merely confused, inherent meanings; we cannot engage with the music, are rarely negated and rarely affirmed. Such an experience can be boring, but it can also be more forceful and quite painfully aggravating or irritating. When musical style is this unfamiliar, we may well find the music random or incoherent. Our experience is fragmented, tossed to and fro on apparently unrelenting, arbitrary waves of meaningless movement.

Such an experience can be illustrated by an anecdote of a music student in a class on the twentieth-century atonal composer Schoenberg. On listening to the vocal and instrumental piece 'Mondestruncken' from his Pierrot Lunaire, she declared she found the music incoherent, chaotic and random, and that listening to it was like a form of slow torture. Unfamiliarity with Schoenberg's compositional procedures and the style of the music in general, had prevented her noticing a high level of organisation of the musical materials, for example a distinctive seven-note motif which is uninterruptedly repeated four times in the flute at the beginning, repeated again and taken up in varied forms by other instruments throughout the rest of the piece. As a result of her unfamiliarity with such stylistic factors, amongst others, she received few meanings from the music, which is one reason why she had such a negative response to it. 
We are uplifted, affirmed, bored or aggravated by music's inherent meanings in as many different ways as the diversity of musical style and of our individual understanding and prior experiences imply. Similarly, we can have a range of responses from positive to negative in relation to delineated meaning.

At one extreme we have a positive response when we feel the music in some way expresses our feelings, when we identify with the music because it delineates our social class or supports our political values, when it affirms our preferred clothing, hair-style, our age, ethnicity, gender and many other factors. At the other extreme we can have a negative response when we feel the music delineates social or political values of which we disapprove or from which we want to disassociate ourselves, social groups from which we are excluded, and so on. To illustrate such responses here are two snippets from Bennett's ethnographic work with Asian youth and their relationship with Bhangra music in Newcastle, UK in the late 1990s. Some used it to celebrate 'tradition', and valued it as a family music crossing generations; others rejected it as a way of articulating their separateness from these same traditions and family values. For example:

It's good to go to a bhangra event because...it brings back memories...it's like tradition. It's the same with the dancing like. There is a traditional dance...nowadays some people just move how they want to. But I think it [the traditional bhangra dance] does matter in some ways, 'cause it gives you a buzz to be doing something a bit traditional. (Bennett, 2000, p. 111)

Alternatively:

I was brought up listening to bhangra, because that's what my parents listened to...there was nothing else to listen to really. Then, as soon as I got to about thirteen or fourteen...I had different friends, white friends, and a different kind of atmosphere. I started listening to their tapes and I'd find out what I really liked which is dance music... Now I can't stand bhangra. (p. 117)

What is meant by 'I can't stand bhangra'? Is it that the person is aggravated by the inherent meanings of the music, or negated by the delineated social values the music carries? It would not be unreasonable to assume that our responses to inherent and delineated meanings usually correspond. If we dislike the one we are likely to dislike the other. For example, if we are already negative to music's delineations, we are unlikely to 
be affirmed by its inherent meanings; and indeed, unlikely to get ourselves in a position to become sufficiently familiar with its inherent meanings for affirmation to take place. If school children are perfectly sure that Western classical music is intended only for 'boffins' and very boring adults (delineations), they are likely to dismiss its inherent meanings as being equally boring. They will therefore avoid listening to it and for that reason will continue to be unfamiliar with its inherent meanings; and for that reason in turn are highly unlikely to suddenly get a kick out of listening to the Scherzo of Beethoven's Ninth Symphony. Conversely, if our responses to inherent meanings are already negative, it is likely we will dismiss the delineations too. Some classical musicians today still believe that popular music is wholly simplistic and very easy to play. The pop-musicological challenge to that perception includes the point that such listeners seek the 'wrong' qualities in the music, expecting to hear motivic development for example; and in so doing, miss out on hearing the 'right' qualities, such as timbral change, rhythmic inflection or texture (Middleton, 1990; Brackett, 1995). The Schoenberg student is another example, because not only did she find the inherent meanings tortuous, she dismissed the whole enterprise of modernist abstract art and atonal music as pretentious.

What I term 'celebration' is experienced when a positive experience of inherent meanings is accompanied by positive inclinations towards delineations. Contrastingly, 'alienation' is experienced when a negative experience of inherent meanings is accompanied by negativity towards delineations.

But sometimes the two aspects of musical meaning are in contradiction, and this will engender an experience of 'ambiguity'. There are two ideal types of ambiguity. In one of these, the experience of inherent meaning is negative, whilst that of delineated meaning is positive. For example, we can think of a person who dislikes Mozart's music and hears it as boring, frilly and superficial. As a result he hardly ever listens to it, which means in turn that his familiarity with the style is quite low. All in all such factors are liable to make him negative towards the inherent meanings. But at the same time, he can nonetheless approve of and identify with the delineations: the practice of taking important overseas business colleagues to the opera, perhaps (he would never consider taking them 
to a rock gig!); the social-class values with which the music is associated in his mind, and so on. He is thus positive towards the music's delineations.

Alternatively, experience of inherent meaning can be positive whilst that of delineated meaning is negative. In such a case we can think of the classical music-lover who is totally familiar with the inherent meanings of Wagner's music, say; who has perhaps listened to, played or sung his music for many years, and has thus developed a profound knowledge of the style, allowing her to be thoroughly affirmed by the inherent meanings. But, simultaneously, she has strong antipathies to Wagner because of his renowned antisemitism and the harnessing of his music by Nazi Germany; or perhaps she simply dislikes going to the opera because she thinks the rest of the audience are 'stuffy'; or she is critical of most operatic plots because she finds them sexist, racist, and so on.

Not only may the quality of the response to each type of meaning contradict the other, but something else can occur which is perhaps one of the most provocative aspects of music, and raises some interesting issues for music education. This is that the response to one aspect of meaning can overpower, influence and even change the other.

On one hand, delineation can override inherent meaning. For example, a late nineteenthcentury Scandinavian music critic was in the habit of writing very positive reviews about a particular composer. After many reviews, he found out that the composer was a woman. He carried on writing good reviews, but his language changed. Instead of using words like 'strident', 'virile' or 'powerful', he began to use words like 'delicate' and 'sensitive'. What had happened was that the gender of the composer had entered the delineations of the music for this listener, as a problematic aspect that challenged contemporary assumptions about gender, musical practice and compositional creativity. This new delineation then affected the way that the critic heard the inherent meanings (Green, 1997).

On the other hand, the notion that inherent meaning can act back to change our perception of delineation appears at first to be a logical impossibility. For inherent meaning is devoid of content; it exists as a virtual aspect of musical experience, which can itself only occur if there is also a delineated content. However I will argue at the end 
of this article that experience of inherent meaning can indeed change, and challenge, our musical responses to and presuppositions concerning delineation; and that it is in this moment of musical autonomy, that the most critical power of music resides.

\section{Musical experience and social reproduction}

Music education in schools for most of the twentieth century took it for granted that the musical experience and needs of all children were fundamentally the same. All students were required to engage in music whose inherent meanings ranged from being affirmatory for some of them, to being wholly alienating for others; and whose delineations corresponded or conflicted with the students' social class and family backgrounds, self-images, public or private identities, values and desires. Music education is intended to enhance and appraise students' musical abilities, but at the same time there may be something else altogether going on. This proposition can be considered on two levels, one reflecting the experience of the individual student, in all the diversity that implies; and the other concerning the production and reproduction of large-scale social groups and corresponding patterns of advantage and opportunity, to which the education system makes such a powerful contribution. I will briefly consider these two levels and in so doing, illustrate the role of the music classroom in the production and reproduction of two social groups in particular, class and gender.

There is little disagreement nowadays that in its concentration on Western classical music for at least the first three-quarters of the twentieth century, music education participated in the construction and perpetuation of certain ideologies about musical value that privileged this musical style. These ideologies involved placing a high value on qualities said to be possessed by classical music, notably those of its autonomy from particular social interests and contexts; its corresponding ability to express a 'universal' human condition; its eternality, which was also related to its universality; and its formal complexity, (which was paradoxically related to the social convention of notation, on which it relies for its transmission). The school classroom afforded greater opportunities for educational success in music to those children from social class backgrounds that equipped them with commensurate practices and values regarding classical music. This occurred partly with regards to access to resources such as musical instruments and private tuition. Indeed, the assumption that such access was a pre-requisite of musical 
success was even written into exam syllabi, explicitly in the 1950s, then implicitly, right up to the middle of the 1980s (Green, 1988).

This was by no means only a question of access, for pupils' relationships to musical meaning are a more trenchant factor. Affirmation by the inherent meanings of the music being studied is as advantageous as affinity with the music's delineations, allowing for possible 'celebration' by the music in the classroom. These positive responses to both inherent and delineated meanings, of course derive largely from students' having family and social class backgrounds in which classical music is listened to and valued, so that they are already well equipped in Bourdieu's terms, with what the school demands but does not provide (Bourdieu, 1973: 80). Many of those pupils who did not have such backgrounds appeared to lack both interest and ability in music, concealing the fact that a small but significant minority of them were deeply involved in other musical styles related to quite different learning practices outside the school, such as playing in pop, rock or jazz bands (Green, 2001). But it was not only the musical practices in which pupils were or were not engaged that caused this fissure in the institutional recognition and reward of musical ability. For musical experience itself, in which pupils found themselves being celebrated or alienated, or through which they had ambiguous musical experiences, is more fundamental. I will return to the significance of this at the end of the article.

Another factor in the music classroom's production and reproduction of social groups concerns the invisibility of the reproduction processes. These were perhaps buried even more deeply, and ironically so, by virtue of an appearance of increased equality of opportunity which started to occur in the late 1980s, when a wider range of music was included in the school curriculum in many countries (Green, 2002). For since popular, jazz and 'world' musics were, at last, accepted in the classroom, this appeared to afford greater opportunities to pupils from a much wider range of social groups than hitherto. But there were two problems here. One was that teachers still tended to operate within an aesthetic of classical musical autonomy, only they referred this aesthetic to a wider range of musics. So popular musics, jazz and 'world' musics were assumed to have some amount of autonomy, universality, eternality and the capacity to express the human condition, especially in their ability to cross cultural boundaries. Such a position therefore 
appeared to place equal value on a wider range of musics, whilst actually continuing to uphold an aesthetic position that was fundamentally derived from classical paradigms, and was not necessarily applicable to most of these 'other' musics in the world outside the school (Green, 1999). The other problem was, and continues to be, that teachers tend to be largely trained in classical music themselves, and to adopt twentieth centuryderived classical pedagogical approaches, which ride roughshod over the informal learning practices by which most of these other musics have always been transmitted. Thus, although there is new content in the music classroom, the teaching strategies mitigate against its authenticity. The musics in that sense exist inside the classroom as shadows of their 'real' forms (Green 2001).

The majority of pupils who choose to sing and play classical music, or the music provided and organised by their teachers in schools, especially in extra-curricular activities, are girls. They are also widely regarded by teachers as being more successful at music, more tolerant, hard-working and reliable than boys. Meanwhile boys are generally said to avoid music because of its 'cissy' connotations, restricting their involvement to those areas of musical activity that signal the least approval, and the least supervision, by teachers (Green, 1997; Hanley, 1998). However, as distinct from the hard-working obedience of girls, it is not despite but because of boys' negative attitudes, that teachers attribute boys with the qualities of creativity and genius which girls are seen to lack (Green, 1997).

Again this involvement of music in reproducing age-old gender assumptions does not stop merely at the level of pupils' musical practice and teachers' perceptions of it. It goes further, in that the music involved takes on corresponding delineated meanings. As the discourse of both pupils and teachers shows, to a large extent classroom-approved music comes to delineate femininity, and more radically, effeminacy. By the same token, popular music, or any music that is not included in the curriculum or extra-curricular activities, and not taught by the teacher, delineates masculinity, and beyond that, machismo. It is not merely a matter of 'feminine' practice that girls play the violin, or of 'masculine' practice that boys play the electric guitar; but musical experience itself, and with it, the very construction of gender as a symbol of self, are at stake. The music in which girls and boys are involved acts back through these gendered delineations, to bring 
a symbolic affirmation, or a problematisation of their gender identity. So as with social class reproduction, musical experience itself, in the context of the school, actually produces and reproduces not only gendered musical practices but gender identities and with them, gender itself.

By similar processes other social groups are produced and reproduced in the music classroom. For example, many schools incorporate 'world music' to reflect and celebrate the ethnicity of their pupils. But, as Bennett's work illustrates (above), this can backfire. Alden (1998) found that primary school children in London concealed their 'true' Hindi popular music identity and pretended to prefer the pop charts, to avoid being stigmatised by the 'white', mainstream culture, which prevailed in their classroom, despite the school's anti-racist policies and multi-cultural curricula. Other social groups, from largescale religions to small-scale local scenes, can be similarly affirmed or denied by the music classroom, forming themselves not only through its purview, but precisely, in contradistinction to the music and musical experiences that the classroom offers.

In classrooms, some pupils will find themselves musically celebrated by positive relationships to both inherent and delineated meanings; others will be alienated, and for others, musical experience will be ambiguous. The reasons are not to do with innate musical ability, but are the result of family and social class background, membership of different social groups, and prior listening experiences. But I have been suggesting that it is not merely that the music classroom makes available, rewards or negates musical experiences; something else is going on which is more interesting and more powerful. Since music itself carries meanings for us, therefore reproduction occurs through musical experience itself. As I argued earlier, the distinction between the two aspects of musical meaning that I have suggested in this article is a logical one, but when we engage with music the two aspects come to us experientially as one unified whole. We do not usually, and often cannot, distinguish the one from the other, just as we find it hard sometimes to distinguish different kinds of love from each other. Because of this, the delineated meanings of music appear to come to us as if they were a part of the inherent meanings, the 'music itself'. So our responses to inherent meanings appear to be visceral; the inherent meanings appear to contain the delineated meanings as if those meanings did 
reside inside the music. Thus they seem to be immediate, that is, un-mediated by history and convention, not constructed, but natural, unquestionable and 'true'.

\section{Retrieving autonomy}

If music is such a conservative force, and music education along with it, do either of them also have the capacity to change things? This is where I wish to reach for that discarded concept of musical autonomy. Where the concept becomes problematic is when it goes so far as to completely deny the importance and relevance of music's social contexts or delineations, focussing instead on the musical text or inherent meanings in ways that either explicitly or implicitly suggest that these are the only 'real' or 'important' aspects of music. Such an approach does indeed beg for adjustment so that social and cultural influences on both the production and reception of that text are included in any examination of its full significance. However there are three provisos to this.

One is that there can surely be nothing 'wrong' with musicologists focussing entirely on musical texts and ignoring social contexts, so long as it is done in the recognition that they are only concerning themselves with some, out of many possible, aspects of the music (Green, 2000). Secondly, historical musicology has in any case always concerned itself with the social contexts in which the music studied was originally produced, and with the music's reception at the time of origin and beyond. It may be that such work did not concern itself with certain aspects of those contexts, such as the roles of women in music; but that is a different matter. Thirdly, it is only because music does indeed retain some level of autonomy from social contexts that it can exist at all. Music cannot be whatever people say it is. Any attempt to suggest that it can be, and thus to altogether deny its autonomy, ironically ends up as a position of idealism (which is the very accusation levelled at the autonomists, but for different reasons!). For it presupposes that music has no objective properties, that its materials are immaterial, so to speak, as if music could be made out of any material whatsoever, organised in any way, and still be counted as music. It is partly because we cannot see or touch music, that it is often regarded in such a light; but music is of course an object like any other object in the world, fleeting perhaps, but nonetheless material. And as I suggested earlier, in relation to Gibson's terminology, certain music affords certain responses rather than others. 
Not only is it unwise in a logical sense to totally dismiss the concept of autonomy, but it might also lead to overlooking one of the most critical capacities made available by music. (This notion is more fully developed in Green, 1997: 249-56. D. Clarke, 2003 suggests a similar perspective.) For example, imagine a social and historical context in which it is generally assumed that a class of teenaged school pupils will not be capable of singing with conviction in an opera, since they are exclusively and jealously interested in pop music; or a context in which it is assumed that women cannot play orchestral instruments confidently, since they are too feeble; or one in which it is assumed that women cannot compose music that is 'strident', 'virile' or 'powerful'; or that white people cannot sing the blues authentically ... Then imagine a situation where you see and hear these very things going on, and where the inherent meanings of the music hit you, not as being somehow lacking, feeble or inauthentic, but the opposite: as musical affirmation.

Such moments, arising from a virtual experience of inherent meanings logically set free from delineations, can explode the apparent 'truth' of the old, taken-for-granted delineations. We touch a quality of musical experience which, precisely because of its logical freedom from delineation, at the same time exposes the inevitability of delineation. The previous assumptions about teenaged school children, women, race or whatever surface. The delineations about them are made audible. Then a host of new delineations, new conceptions, both of music and of teenagers, women, race and so on become possible. It is through such experiences of inherent meanings as logically separable from delineation, and thereby as potentially open to any content, that new musical and social horizons can appear.

So in that sense I would say that music can cross boundaries, and has done so many times in its long history. This is one reason why music education continues to be worthwhile: for although education has reproductive effects such as those I have considered earlier, it also offers us the potential to challenge our understanding and awareness at a deep, symbolic level, through bringing together new and previously disparate meanings and experiences. Of most particular significance here is that such moments may be most forceful when we engage with music not only as listeners but as music-makers. In making music, students have a direct effect upon inherent meanings, indeed bring them 
into being, and are thus able to imbue the music with a delineated content of their own. The potential freedom, or autonomy of such content from previously taken-for-granted assumptions and definitions is thus potentially exposed. It is precisely by acknowledging music's logical moment of autonomy from social contexts, that we reveal how readily music becomes filled with social content and significance. At the same time therefore, this perspective carries a caution: against making any assumptions about how music is understood by others.

\section{Bibliography}

Alden, Andrew. (1998) What does it all mean? The National Curriculum for Music in a multi-cultural society (unpublished MA dissertation, London University Institute of Education).

Bennett, Andrew. (2000) Popular Music and Youth Culture: Music, Identity and Place (London and New York, MacMillan's Press).

Bourdieu, Pierre. (1973) Cultural reproduction and social reproduction, in R. Brown (ed.), Knowledge, Education and Cultural Change (London, Tavistock).

Brackett, David. (1995) Interpreting Popular Music (Cambridge University Press).

Clarke, David. (2003) Musical autonomy revisited, in Clayton et al, The Cultural Study of Music: A Critical Introduction (New York and London, Routledge).

Clarke, Eric F. (2003) Music and Psychology, in Clayton et al, The Cultural Study of Music: A Critical Introduction (New York and London, Routledge).

Clayton, Martin, Herbert, Trevor and Middleton, Richard (eds). (2003) The Cultural Study of Music: A Critical Introduction (New York and London, Routledge)

De Nora, Tia. (2000) Music in Everyday Life (Cambridge University Press).

De Nora, Tia (2003) After Adorno: Rethinking Music Sociology (Cambridge University Press)

Finnegan, Ruth. (1989) The Hidden Musicians: Music-Making in an English Town (Cambridge University Press).

Gibson, James. (1986) The Ecological Approach to Visual Perception, (first printed 1979) (London and Hillsdale, NJ, Lawrence Erlbaum). 
Green, Lucy. (1988) Music on Deaf Ears: Musical Meaning, Ideology and Education (Manchester and New York, Manchester University Press).

Green, Lucy. (1997) Music, Gender, Education (Cambridge University Press).

Green, Lucy. (1999) Ideology, in Bruce Horner and Thomas Swiss (eds), Key Terms for Popular Music and Culture, (New York and Oxford, Basil Blackwell).

Green, Lucy. (2000) On the evaluation and assessment of music as a media art, in Rebecca Sinker and Julian Sefton-Green (eds) Evaluation Issues in Media Arts Production, (London, Routledge).

Green, Lucy. (2001) How Popular Musicians Learn: A Way Ahead For Music Education (London and New York, Ashgate Press).

Green, Lucy. (2002) From the Western classics to the world: secondary music teachers' changing perceptions of musical styles, 1982 and 1998, British Journal of Music Education, 19:1.

Hanley, Betty. (1998) Gender in secondary music education in British Columbia, British Journal of Music Education, 15:1.

Martin, Peter. (1995) Sounds and Society: Themes in the Sociology of Music (Manchester and New York, Manchester University Press).

Meyer, Leonard B. (1956) Emotion and Meaning in Music (Chicago and London, University of Chicago Press).

Middleton, Richard. (1990) Studying Popular Music (Milton Keynes, Open University Press).

Moore, Allan. (2002) Rock: The Primary Text: Developing a Musicology of Rock, London and New York, Ashgate Press; originally published as Rock: The Primary Text (Buckingham, Open University Press, 1993).

Negus, Keith. (1999) Music Genres and Corporate Cultures (London and New York, Routledge).

Swanwick, Keith. (1984a) Problems of a sociological approach to pop music in schools, British Journal of Sociology of Education, 5:1.

Swanwick, Keith. (1984b) A further note on sociology of music education, British Journal of Sociology of Education, 5:3.

Vulliamy, Graham and Shepherd, John. (1984a) The application of a critical sociology to music education, British Journal of Music Education, 5:1. 
Vulliamy, Graham and Shepherd, John. (1984b) Sociology and music education: a response to Swanwick, British Journal of Sociology of Education, 5:1.

Vulliamy, Graham and Shepherd, John. (1985) Sociology and Music Education: a further response to Swanwick, British Journal of Sociology of Education, 6:2. 


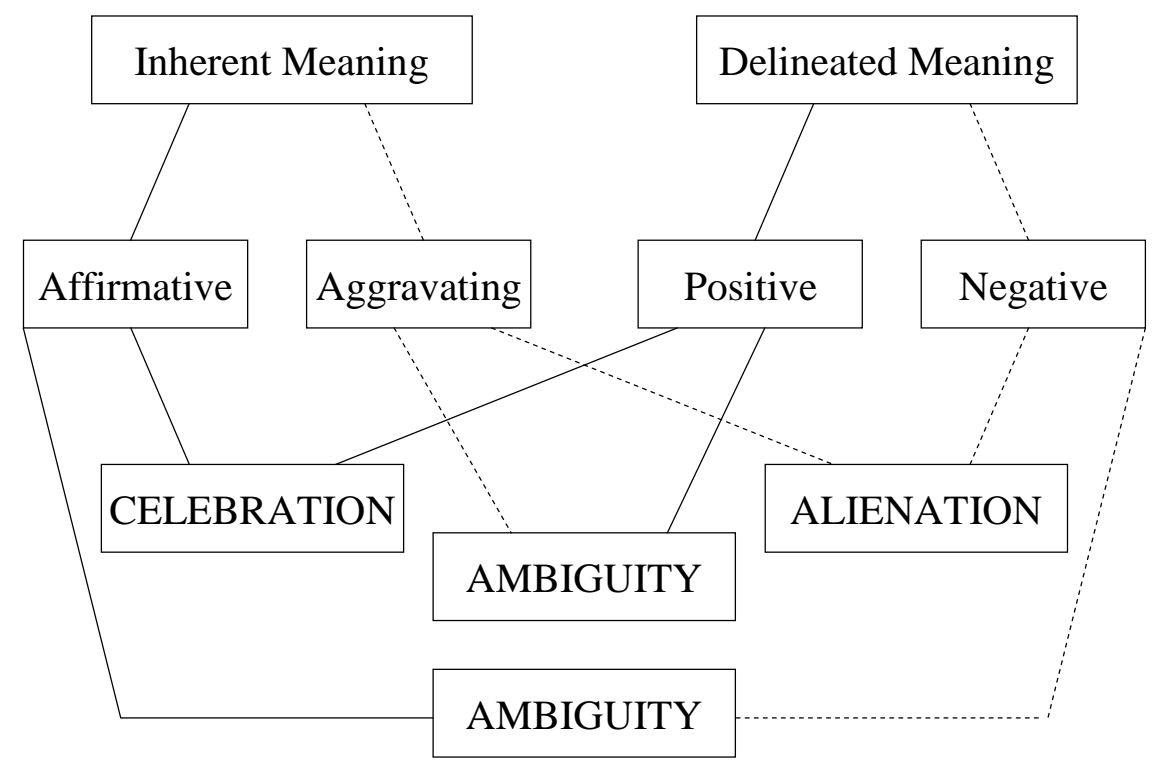

(Adapted from Green, 1988: 138 and 1997: 251)

\section{Chart A}

